\title{
Fostering Empathy in an Undergraduate Mechanical Engineering Course
}

\section{Dr. Joachim Walther, University of Georgia}

Dr. Joachim Walther is an associate professor of engineering education research at the University of Georgia (UGA). He is a director of the Collaborative Lounge for Understanding Society and Technology through Educational Research (CLUSTER), an interdisciplinary research group with members from engineering, art, educational psychology and social work. His research interests range from the role of empathy in engineering students' professional formation, the role of reflection in engineering learning, and interpretive research methodologies in the emerging field of engineering education research. His teaching focuses on innovative approaches to introducing systems thinking and creativity into the environmental engineering program at the University of Georgia.

\section{Dr. Shari E. Miller, University of Georgia}

Shari E. Miller is an Associate Professor and the Associate Dean of the School of Social Work at the University of Georgia. Her research focuses broadly on social work education and the social work profession with specific areas ranging from educational innovation, thinking in and for social work, development of theory, inter- and trans-disciplinary and inter-professional education and practice, and professional socialization. She has experience teaching across the social work education continuum, with an emphasis on theory, practice, and the relationship between theory, research, and practice. She is engaged in an ongoing collaborative research program with colleagues from engineering to develop inter-disciplinary approaches to education for reflective inter-professional practice in a global society. She also collaborates with colleagues from multiple disciplines on community engaged projects focused on sustainability.

\section{Dr. Nicola W. Sochacka, University of Georgia}

Dr. Nicola W. Sochacka received her doctorate in Engineering Epistemologies from the University of Queensland, Australia, in 2011. She is currently a member of the CLUSTER research group at the University of Georgia where she holds a research and teaching position. Nicola's areas of research interest include: STEAM (STEM + Art) education, diversity, interpretive research quality, the role of empathy in engineering education and practice, and student reflection.

\section{Mr. Michael Alvin Brewer jr., University of Georgia}

University of Georgia 


\title{
Fostering empathy in an undergraduate mechanical engineering course
}

\begin{abstract}
Engineers are increasingly being called upon to infuse a deeply considered, empathic regard for a broad range of stakeholders into their work. This development can be attributed to a growing recognition of the socially-situated nature of engineering practice and the shared and interdisciplinary nature of today's grand challenges. In order to prepare engineers to more effectively address these challenges, we contend that empathic ways of interacting with others need to be explicitly fostered in undergraduate engineering programs. Pedagogical approaches to teach empathy to engineering students, however, are limited. In this paper, we describe the development and pilot implementation of a set of four empathy modules that we integrated into a sophomore mechanical engineering course $(n=110)$ at a large state university. We used a theoretically-grounded, context-specific model for empathy in engineering, which conceptualizes empathy as a teachable and learnable skill, a critically reflected-upon practice orientation, and a professional way of being, as the basis for developing the modules. Drawing on detailed observation notes and critical reflections, we provide an account of how the modules were received by the students and the lessons we learned with the view to further refining the modules for future iterations. In parallel, we discuss early insights concerning the potential impact of integrating explicit instruction in empathy into undergraduate education on the professional formation of engineers.
\end{abstract}

\section{Introduction}

In 2012, the University of Georgia established a new College of Engineering. This new entity was motivated by the desire to educate a different type of contemporary engineer - one who is not only technically excellent but also innovative and aware of the inescapable humanistic aspects of working in complex socio-technical systems ${ }^{[1-4]}$. This vision of the "UGA engineer" has informed the curricula development for the College's eight undergraduate programs. In the Mechanical Engineering program, this vision led to the implementation of a design sequence that includes a compulsory, 3 credit hour, sophomore class that focuses on engineering and society (Engineered Systems in Society: MCHE 2990). In this paper, we describe the development of a set of four empathy modules that we have created as a core and integrated element of this course and preliminary observations from their implementation in fall 2015. We begin with a brief explanation of our motivations and rationale for including explicit instruction in empathic ways of thinking in an engineering context. We then present the theoretical basis we used to design the modules. Next, we describe the course setting and model implementation. And finally, we offer an account of lessons we are learning with regards to how to instruct engineering students in empathic ways of communicating and engaging with others and how we envision these skills as intersecting with and supporting other aspects of engineering students' professional formation.

\section{The need for empathy in engineering}

As we write this paper, the media is abuzz with news of elevated levels of lead in children's blood in Flint, Michigan. Residents are blaming the crisis on a recent change of the water source 
from Detroit's water system to the Flint River, the timing of which coincides with the elevated lead levels. Reading about the revelations in Michigan brings to our minds the discovery and attempted cover-up of lead in the Washington D.C. water supply, which Drs. Donna Riley and Yanna Lambrinidou wrote about in their 2015 ASEE paper, "Canons against Cannons? Social Justice and the Engineering Ethics Imaginary” [5]. Similar to in Washington D.C., Flint State officials are being accused of failing to act soon enough and in the best interests of the citizens. Both of these cases highlight the inherent socio-technical nature of engineered systems - a feature of engineering which, we and many others have argued, is too often overlooked or underemphasized both in engineering practice ${ }^{[1-4]}$ and education ${ }^{[6-9]}$. To us, these examples also highlight the critically important need for engineering practitioners to master and integrate technical and empathic ways of thinking.

According to Levenson and Ruef ${ }^{[10]}$, empathy comprises three essential qualities including: the cognitive component - knowing what another person is feeling, the emotional component feeling what another person is feeling, and the responding component - responding with compassion to another person's experience. Taking the implications of empathy beyond one-onone interactions and squarely into the broader contexts in which they take place, Segal ${ }^{[11]}$ offers a theoretical framework for social empathy, which she defines as, "the ability to understand people by perceiving or experiencing their life situations and as a result gain insight into structural inequalities and disparities.” Through developing social empathy, Segal argues that "[i]ncreased understanding of social and economic inequalities can lead to actions that effect positive change, social and economic justice, and general well-being.” (p. 267). It is this expanded form of empathy that we contend engineers must develop in order to effectively practice in contemporary, socio-technical systems.

To this end, we have established a long term working relationship between engineering and social work to develop a context-appropriate and intellectually robust, theoretical understanding of empathy in engineering ${ }^{[12]}$ and, in parallel, practical educational interventions to explicitly foster empathy in engineering students ${ }^{[13,14]}$. Below, we briefly outline the results of our prior theoretical development efforts, which informed the design of the four empathy modules we implemented into the sophomore engineering and society class.

\section{A context-appropriate and intellectually robust model of empathy in engineering}

The model of empathy in engineering presented in Figure 1 emerged from a four year interdisciplinary dialogue between the first three authors of this paper (two researchers from engineering education and one researcher from social work education). This dialogue was motivated by prior research that called for a "unified and conceptually cohesive language for applying empathy" ${ }^{[15]}$ to an engineering setting; with the same authors suggesting that research informed by long standing traditions in other fields may provide the "rigor, conceptual clarity, and research expertise" ${ }^{[15]}$ necessary to theoretically ground the education and practice of empathy in technical fields. The development of the model was also informed by a critical synthesis of the literature pertaining to empathy in the fields of social work and engineering. In the following paragraphs, we summarize the key features of the model and direct our readers to

${ }^{[12]}$ for a detailed account of the model development and its theoretical underpinnings. 


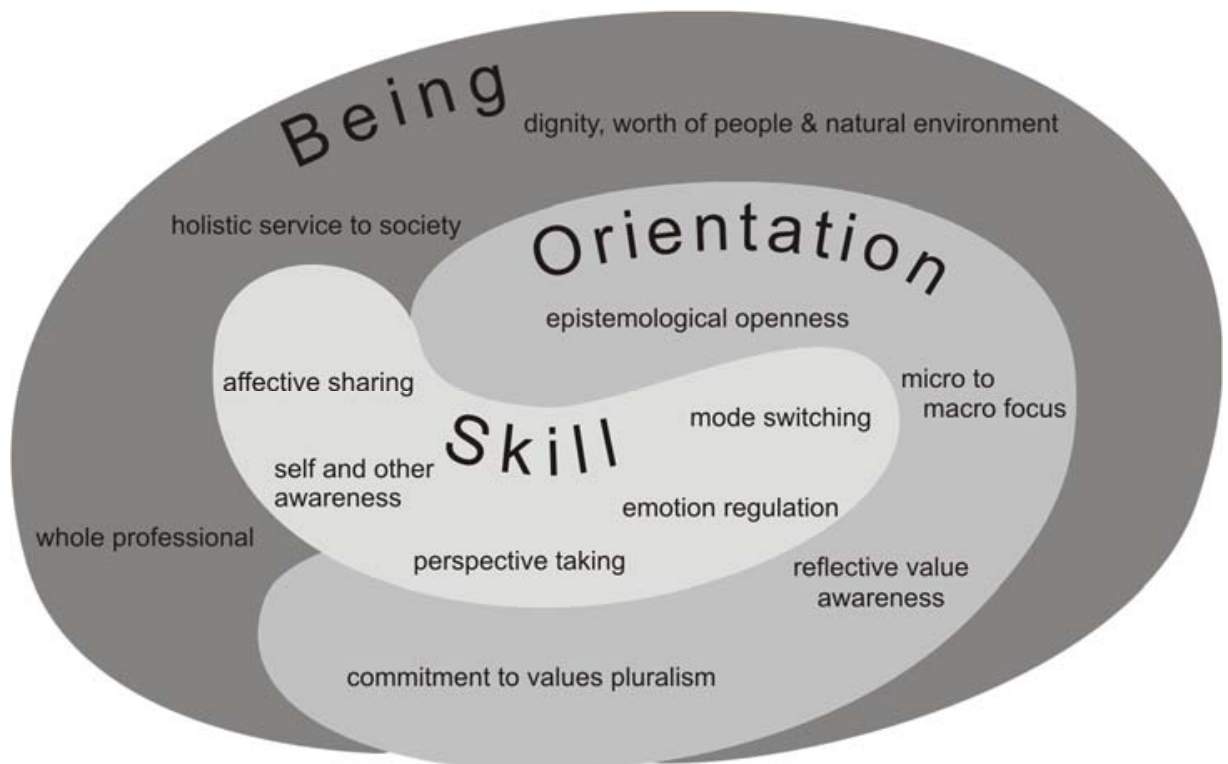

Figure 1: Empathy in engineering - A neurobiologically-inspired, context-appropriate, and theoretically robust model.

The model in Figure 1 comprises three dimensions that illustrate dynamically interrelated and integrated facets of empathy in the context of engineering. More specifically, the model conceptualizes empathy as a skill, a practice orientation, and a professional way of being, and is purposefully composed to illustrate the mutually dependent and supportive nature of each dimension without ascribing a conceptual hierarchy or developmental trajectory.

The skill dimension is anchored in neurobiologically established functions present in all humans $[16,17]$ that are, in the model, complemented by the engineering specific facet of mode switching to acknowledge that analytic and empathic content can be simultaneously present in engineering communication. The main implication of this part of the model is that empathic skills are concretely teachable and that engineering educators can specifically draw on and leverage students' existing, albeit variably developed, empathic capacities.

The facets included in the practice orientation dimension highlight a range of habits of mind and predispositions that orient practitioners to think, make decisions, and act in particular ways in professional settings. In other words, while the facets of the skill dimension describe what an individual can do, the practice orientation dimension captures why, how, or whether an engineer might embody these skills in practice - what they will do in a given situation. The key implication of this dimension of the model is that empathic skills can neither be developed nor embodied in practice without attending to aspects of epistemology and values engagement that profoundly inform engineering work. For the educational context, this recognition implies a need to purposefully and critically explore the often implicit orientations that inform engineering education and to situate efforts to develop empathic skills explicitly in the context of such explorations. The need to attend to students' developing practice orientations also offers an opportunity to pedagogically link the empathic skill development with the necessary broader discussions of overarching ethical frameworks that inform the being dimension of the model. 
Finally, the being dimension acknowledges the need for an overarching values framework to inform and guide the development of the facets of empathy along the skill and practice orientation dimensions. If the skill dimension describes empathy as what we can do, and the orientation dimension as what we will do in a given situation, the being dimension captures how we fundamentally think and feel about the situation, our actions in it, and our role as engineers in the world. This dimension draws and builds on the relatively well-developed discourse of ethics in the engineering education community ${ }^{[18-23]}$ and related literature in other fields. The inclusion of a broader ethical perspective as part of the model is necessary to provide the intended conceptual coherence, in other words, to see the full picture of what it means to develop and embody empathy in engineering. The being dimension thus indicates that in order to conceptually define and pedagogically support empathy in engineering, engineering educators need to critically and reflexively engage with larger ethical commitments and moral principles.

\section{Integration of empathy modules in a project-based engineering and society course}

Based on the theoretical model described above, we designed and implemented a series of empathy modules into a sophomore engineering and society course that is part of the abovedescribed, new, mechanical engineering curriculum at the University of Georgia. The goals of the project were to: (i) achieve a substantive integration of the modules within the overall course design and alignment with other course elements, and (ii) provide students with contextually relevant opportunities to experience and explore the entire conceptual space of empathy as a skill, practice orientation, and way of being. The following provides an overview of the targeted course and relevant pedagogical features to set the context for the subsequent detailed description of the modules.

\section{Course context and features}

The modules were integrated in a sophomore level engineering and society course (MCHE 2990) that is a compulsory component of the design sequence in the mechanical engineering curriculum. The iteration we describe in this paper was taught by the first author in fall 2015 and enrolled 110 students who were split into two groups of 55 for the facilitation of the modules.

The course design for MCHE 2990 combines group-based, open-ended design challenges that focus on problem-framing in complex, socio-technical contexts, with a series of readings and critical discussions that provide the theoretical and conceptual underpinnings of socio-technical systems. The readings and facilitated group discussions guide students to understand engineering work as inherently socially-situated ${ }^{\text {[e.g., } 24,25]}$ and explore aspects of socio-technical complexity such as the relationship of technology to politics and power ${ }^{[e . g ., 26]}$ or the challenges of sustainable development ${ }^{\text {[e.g., 27]. }}$ Other readings invite students to critically question assumptions around technological determinism ${ }^{[\text {e.g., }}{ }^{28]}$ and perceptions of engineering expertise ${ }^{[\text {e.g., } 29]}$, and explore the relationship between engineering work and a broader service to society ${ }^{\text {[e.g., } 30]}$.

In fall 2015, semester-long, group based design challenges around food and sustainability were designed to offer students opportunities to experientially ground their developing conceptual understandings. More specifically, student teams investigated the broad challenge in specific local contexts with a focus on technical, social, cultural and economic factors. Workshop elements over the semester prepared students to engage in observations of the local context and 
engage with stakeholders to develop and represent a coherent understanding of the chosen context and system. Throughout the course, a range of reflection activities and reflective writing exercises were used to complement the experiential learning opportunities.

\section{Module design and implementation}

The modules were delivered consistently and collaboratively throughout the semester by the first author, an engineering educator, and the second, a social work educator. The design of the modules, which are introduced in more detail below, was based on a number of features to provide a coherent and integrated experience for students. More specifically, the modules each comprise a set of structured exercises to facilitate the development of the skill dimension of empathy. These exercises are drawn from the pedagogical traditions of social work and have been adapted to the engineering context.

Building on these exercises, each module contextualizes students' developing skills in a continuous application scenario in a professional engineering context. The applied component of each modules moves from somewhat abstract experiential activities, to context-specific location of the material in a real-world engineering practice space. The scenario (see Box 1 for initial scenario description) was inspired by the larger, local, social context of the town in which the university is located and progressively developed over the course of the four modules.

Box 1: Case scenario

Case Scenario applied across all Modules: Food security and social sustainability

You are an engineer working in Athens. The history and demographics of the city include extremely high poverty rates accompanied by extremely high rates of food insecurity. In addition to the general context of poverty and food insecurity, it is important to note that there are clear disparities across race, ethnicity, and age that inform this context. The city has received a large grant to address the issues of food insecurity with an emphasis on environmental and social sustainability. As the engineer you will be working as part of an interdisciplinary project team, and in collaboration with community stakeholders to determine how best to use the grant funds to address these issues in the context of this community's social and environmental landscape. In order to engage in this project, you will need to communicate with professionals from a variety of backgrounds including, landscape design, public health, social work, nursing, and medicine, and with multiple groups of community stakeholders, such as families (adults and children), local business owners, and school teachers and administrators.

Facilitating both components of the modules relies on the subtle interplay of experiential elements and guided debrief sessions that elicit students' reactions, engage their potential discomfort with the unusual learning environment, and distill insights and lessons learned.

After each module, students were asked to complete individual guided homework reflections to provide opportunities for individual sense-making, introspection, and consolidation of learning outcomes. 


\section{The four empathy modules}

In order to capture the overall integrated landscape of the four modules, this section includes a summative overview of the essential components of each module, including its topical emphasis, an example of a skill exercise, an example of the applied exercise, and an example of the reflective homework prompts. It is important to note that after, and sometimes at multiple points within, each skill and applied exercise, there are facilitated whole-group debriefing discussions.

\section{Module 1}

Topical emphasis: Encountering the other with genuineness. This module serves as a launching point for the series, and invites students to identify the ways in which they communicate with others to begin to develop the skills for, and an orientation toward, critical self-reflection for the effective use of self in the professional role. This module emphasizes the ideas that the way we approach others has profound effects on interactions and the nature of developing relationships, and that one can develop an awareness of the things that have bearing on these effects including one's own intentions, interests, expectations, verbal and non-verbal communication in conveying messages, expressing thoughts and emotions, and/or interpretation of responses/emotions.

Example skill exercise: Students are asked to engage in a Commonality Exercise wherein they need to speak with at least three other classmates whom they do not yet know, and uncover three things which they share in common with each. Students then write reflectively about the mechanics of how they approached people, what signals they observed in counterparts' communication, and how they felt throughout the exercise.

Example applied exercise: In the context of the case study, students are told that the city has organized a street festival to generate visibility for and interest in the upcoming project. The organizers have invited community groups and organizations that have a stake in the project to have a booth and inform visitors about their work. Students are then told that, as the project engineer, they are visiting the street festival and are tasked with making connections to stakeholders and to start conversations that could potentially lead to some of the representatives serving on an advisory committee for the project. Students split into groups of three and alternatively take on the role of the engineer and the organization representatives. The engineer is asked to establish contact and pay specific attention to the points of emphasis for the Module. Students provide feedback between alternating rounds, with a focus on how the engineer came across.

Example reflective homework prompts: Students are asked to submit their response to the reflective questions within a few days of the activity itself in order to maximize the freshness of students' experiences and related reflections. Prompts include: 1) Recount your experience during both parts of the module. 2) What did you experience as challenging? 3) What did you enjoy about the exercise? 4) How do you think the exercises are important in an engineering class, for your own future as an engineer? 


\section{Module 2}

Topical emphasis: Self-awareness and emotional regulation. This module is designed to enhance students' capacity to recognize how they use themselves in communication, and how they can work to develop a conscious use-of-self in professional communication to facilitate effective and meaningful collaborative working relationships. Some specific foci include, the need to notice and potentially moderate one's own discomfort in interpersonal engagement, how important it is to recognize that the use-of-self has profound impacts on how participants in a conversation experience the conversation and therefore the developing relationship, that we can communicate our own experiences and intention in listening through use-of-self, that as listeners, we influence the others' experience of communication, and that we can then "feel with" the other by observing these factors, all leading to the potential for increasingly aware, well-informed, and more refined intentional use-of-self.

Example skill exercise: Students are asked to work in teams of two and follow a series of instructions for body language and proximity exercises that focus on eye contact, personal space, relationship of self to other in the context of the actual physical space, furniture, and props. For example, students are given this instruction first: at a distance of about $8 \mathrm{ft}$, establish and maintain eye contact. Slowly move toward your partner who remains in position, until it becomes uncomfortable for you. Then stop. Observe the approximate distance between you. Describe your thoughts and feelings as you moved closer and closer to your partner. Ask your partner to express what s/he experienced as you approached. Make note of your experience as well as your partner's. There are a number of incrementally additive instructions that build upon this. The exercises conclude with the addition of information sharing and listening. Students are given this set of instructions: Place two chairs in a position and at the angle that is reasonably comfortable for both you and your partner. Some compromise may be necessary. Now, one partner needs to tell a brief story about her/himself (2 minutes or so) and while speaking attempt to be as critically self-aware as possible without interfering with your ability to share your story. Be mindful of your tone of voice, your volume, your speed, your word choice, AND be mindful of your body language (including your facial expressions). Meanwhile, the other partner should focus on HOW you told the story (not so much what you told), and what your voice, tone, body, and face conveyed to him/her about what you might have been FEELING during the telling. And as the listener, please do not speak, but instead try to show through your body language that you are interested in your partner's thoughts, ideas, and feelings.

Example applied exercise: Students are provided, in advance, with a set of character descriptions. These characters reappear over the course of the remaining modules, as identified stakeholders, and ultimately members of a diverse project team. Students are told the following: As the project team's investigation of the context around food security and sustainability progresses, the team begins to gather more in-depth information about the perspectives and experiences of various stakeholders. To inform your idea generation phase you are meeting with two other stakeholders. The meeting takes place in your office in the town hall building and you are wondering how you can create an atmosphere that would encourage the stakeholders to share their perspectives. The two particular stakeholders the engineer encounters include a landscape architect and a local, long-time elementary school teacher. Students are provided with the following instructions: 1) Drawing on the strategies from the exercises and insights from Module 1, the engineer invites the 
visitors to his office and initiates the conversation. 2) You ask questions to get a rich sense of the personal and emotional way in which the interviewee experiences the issue of food security and how they feel about the project. You also try to learn more about the factual context of their experience to complement the research you have done on the issue. 3) Ask questions to get a sense of the personal and emotional ways in which the interviewees experience food insecurity and gather information about the factual context of their experience. 4) To facilitate this difficult conversation, you try to express your affective sharing of their experience by acknowledging key feelings and statements.

Example reflective homework prompts: Students are provided with an additional character vignette that tells the story of a single-father household wherein the family is struggling with notable food insecurity. Detailed description of the characters is beyond the scope of this paper, but this description is designed to ask students to develop understanding of the varying investments of different project stakeholders. They are asked to respond then to the following reflective questions: 1 ) Consider the character vignette of the father whose family is experiencing food insecurity. Try to imagine what a conversation with this stakeholder would be like. Write a portion of the dialogue where the stakeholder shares his sense of frustration and desperation with you. In writing the engineer's portion of the conversation, incorporate the lessons you have learned during the class modules. Pay particular attention to the aspects of affective sharing, emotion regulation, and non-judgment. As necessary include 'stage prompts', descriptions of behaviors or internal thought processes. 2) Based on the dialogue you wrote, reflect on what this means for you becoming a professional engineer. Recount some of the ways you experienced the role play activities in class. How did they inform the way you wrote the dialogue? How would you experience such a situation if it was part of your first job out of college?

\section{Module 3}

Topical emphasis: Affective responding/mirroring. Building on the emphasis in Modules 1 and 2 around self-awareness, perspective taking and emotion regulation, this Module further develops students' practical skills around affective (emotion/feeling) responding and mirroring. Students are reminded of the stakeholder scenarios from Module 2, including the case of the single-father family living in food insecure circumstance. With this they are oriented then to the idea that engineering practice situations around stakeholder engagement can be complex with multifaceted, emotional components and might seem overwhelming and outside of their comfort zone. The Module focuses on applying tangible techniques to better navigate these situations.

Example skill exercise: Following a discussion of the term “affective”, students are asked to complete the following series of activities.

1. Recall the most challenging situation you encountered this semester. This can relate to this course, other courses or experiences outside school.

2. In your group of two, take turns to share the details of the specific experience with your partner. Focus on the following aspects to facilitate a productive reflective process:

a. What was the situation? What led up to it? What did you do/ say? What did other people do/ say? What happened afterwards. 
b. How did you experience the situation? How did you feel in the beginning, throughout and after the situation?

c. Stay focused on your own experience! Avoid: generalizations or blaming others.

2. As a listener your task is to practice affective responding. Without interrupting the flow of your partner's narrative (i.e. limit your input to very brief comments, gestures, facial expressions):

a. Acknowledge the emotional experience your partner is sharing with you.

b. Show that you heard, understand and appreciate your partner's experience and its emotional implications.

c. Focus on your role as listener: Don't share similar experiences of your own! Don't try to offer up solutions! Don't try to resolve the other person's issue by making general statements about the nature of the challenges experienced or by locating blame with any of the individuals mentioned in the account.

3. Debrief (after each round):

a. Speaker: What was your reaction to the comments, facial / body expressions your partner offered while you shared your experience? What worked for you? What didn't?

b. Listener: What was your experience of trying to respond affectively? What did you try to do? How successful do you feel your efforts were?

Example applied exercise: In the context of the ongoing project about food security and social sustainability, you have established connections to various stakeholder groups, formed partnerships with stakeholders and other professionals. In developing a portfolio of initiatives to address the overarching project goals, the City Council has identified an opportunity to utilize a vacant city block in a low-income area with an ethnically and racially diverse population to develop and construct an urban natural enclave, including walking trails and community food garden spaces. As the project engineer you plan to approach this initiative by forming a project advisory team comprising a variety of community stakeholders and a range of interdisciplinary professionals. After your initial round of interviews, you have invited some of the stakeholders to a group meeting. Your goals in facilitating this first meeting are: 1) through the group discussion you want to get a richer picture of the individual stakeholders' perspectives as they share their concerns and views with each other, and 2) you want to make sure that all stakeholders are able to hear and appreciate each other's perspectives on the issue of food security and their stake in the urban enclave project. Students are reminded of links to prior modules, and asked to focus on aspects of their use-of-self, to consider any adjustments they might need to make when communicating with various stakeholders, and to regulate their immediate emotional impulses/responses to jump to offering solutions. Students review the stakeholder character descriptions with which they were provided earlier in the course to reinforce their memories about the details; they are then asked to determine who will play which stakeholder role and who will serve as the project engineer. Then, the engineer facilitates the group role played conversation, and the stakeholders engage in the conversation from their particular perspectives, informed by their respective experiences, objectives, and interests.

Example reflective homework prompts: Students are provided with a summary outline of the class activities and then are prompted to: Write a short description of how you experienced each part of the class. Try to answer some of the following questions for each segment: What went 
through your head? What did you experience as rewarding? What was challenging about the exercises? How did you connect the activities to previous modules or other parts of the course? Looking back over your impressions and experiences from today, what are the key insights you will take away from this module?

\section{Module 4}

Topical Emphasis: Synthesis of Prior Exercises with Focus on Mode Switching. This module is designed to pull together the ongoing set of developing skills and orientation, and to build on these with the addition of a focus on mode switching. Mode switching highlights that in engineering practice students will experience the need to move between analytic thought and this conscious use of self. And, given brain structure, it is possible to establish a nimbler capacity to make these switches seamlessly. The emphasis is to continue to bring into awareness the ways of thought, response, and engagement in practice, and how to develop a more empowered and intentional capacity to effectively wield skills for productive practice.

Example Skill Activity: In order to facilitate development of mode switching, students need to be able to identify it when it happens. Author 1 and 3 perform two examples of scenarios involving the project engineer and one of the recurring stakeholders. The first example illustrates effective mode switching. After the role-play, students are asked to identify and articulate where they observed instances of mode switching. With facilitated responding by Author 1 and 3, students' understanding is reinforced. Then Author 1 and 3 offer an example scenario including the same two characters, illustrating the notable absence of effective mode switching. Students are then invited to respond to what they saw, how it differed from the initial example, and how the different approaches had notable effects on the direction, nature, and outcomes of the discussion.

Example Applied Activity: Students are told that the urban enclave project is progressing from the initial building of relationships and the forming of a project team that includes stakeholders as well as other professionals. As the project engineer and project lead, they are told that they have decided to pursue a participatory design approach where the engineer works with the stakeholders in the problem definition and idea generation phase. The engineer has called the second project meeting to continue to build relationships with and among the stakeholders, and begin to explore ideas for the urban enclave project that the members of the group might have. This is a very sensitive phase of the team's development, and as the engineer they have to carefully balance the ideation process with acknowledging and further exploring the stakeholders' perspectives in terms of their interests and aspirations for the project but also their emotional responses, doubts and fears. The students are informed that, in the conversation some stakeholders suggest early ideas that might elicit emotional responses from other members of the group. This dynamic is challenging for the group conversation but also an opportunity to better understand the stakeholders' perspectives and build a shared sense of trust in the group. The engineer, as project director is required to be a moderator in this discussion and must thus explicitly balance some of the analytic aspects of the early ideation with the empathic facets of building relationships and understanding others' perspectives (i.e. mode switching). For those students playing the other stakeholder roles, they are told that it is their charge to try to explore ideas that would address their needs in the project, and that they are also listening to the suggestions of the other members and in so doing, will need to voice some of the reactions or 
concerns they have about them. Students are asked to again review the scenario and character descriptions, to take some notes about what each character might contribute, what their reactions/responses might be, and to also try to incorporate into the process and its unfolding the idea that the engineer as project director has done an effective job in facilitating the group's early engagement so far, and so there is some cohesion and capacity to collaborate (this does not mean there will not be differences, challenges, and a need for empathic responding it does mean that the whole group is better situation to listen effectively). The engineer then focuses on employing the skills and orientation developed throughout the modules, but with a particular focus of adding attempts to mode switch.

Example Reflective Homework Prompts: Students are encouraged to reflect on all four empathy modules and how the four modules aimed to draw together the empathic skills and perspectives they have been working on throughout the semester. They are then asked to: Discuss your experiences of the module today and use this as an opportunity to connect to the prior modules. How do the previously discussed elements come together and how has your understanding of empathy as part of engineering work developed over the course of the semester?

\section{Discussion}

In this section, we share a number of observations we made during the fall 2015 offering of MCHE 2990 and illustrate them with quotes drawn from students' reflections after participating in the modules. These observations are offered here not as a comprehensive analysis of the data, or as an evaluation of the effectiveness of the modules, but to provide the reader with insight into some of the key challenges of fostering empathy in an engineering course, some of which also point to broader, systemic issues that shed light on the persistent challenges around educating for empathy discussed in the engineering education literature.

One key lesson that we learned while facilitating the modules was that purposefully fostering empathy in an engineering setting inherently necessitates learning modalities that are outside of engineering students' comfort zones and the instructional culture of engineering programs. As instructors, we experienced this tension between students' expectations for the class (as likely informed by past educational experiences) and their encountering of the interactive modules through their facial expressions, body language, and a certain reticence in initiating the activities presented. The large class setting also seemed to contribute to the presence of a threshold activation energy for the students that, as instructors, we had to help overcome through showing enthusiasm and offering encouragement.

In their reflections, students articulated their discomfort as the awkwardness they experienced throughout some of the exercises. As one student elaborated:

"As we sat next to each other and conversed [in Module 3], I recalled how strange I felt in Module 2 when I talked so closely to another member of the same gender while trying to maintain eye contact."

Another student specifically discussed the role play activities as follows: 
"In the second exercise, the role-play, the same awkwardness that occurred in past roleplay experiences crept back into play."

Stepping back from their immediate feelings of discomfort, students were also able to recognize the novelty of the experience and how the empathy modules differed from their prior educational experiences:

"The exercise we did in class was a very unusual one, in terms of it being in an engineering class. Usually in an engineering class there's not as much activities that require getting up and communicating and carrying a conversation.”

In discussing their learning progression, students similarly acknowledged the difficulty in developing an empathic perspective in the context of the in-class activities:

"Thursday's role play proved to be a fairly difficult thing to do. It is hard to try and empathize from a foreign point of view looking at an imaginary project."

This perceived lack of realness of the exercises and scenario was echoed by another student as an obstacle in their engaging with the exercises:

"The group exercise was very interesting because none of us really felt as though we were the person we were portraying making it hard to have a real conversation so that we could use and implement what we had learned."

Considering our experiences as instructors and the student perspective reflected in the above quotes, we can offer a number of insights into facilitating these types of learning experiences. In our interactions with the students and during the debriefing segments, we made a point to acknowledge the potential awkwardness and the unusual nature of the exercises and invited students to embrace this experience as an opportunity for significant learning. Further fostering a safe learning environment with opportunities to take risks, as instructors we engaged in the role play in other activities to either demonstrate the process or offer an example to the group for discussion and analysis.

Students acknowledged the value of these elements for their own experience:

"As in the past two modules, it was significantly helpful to view a live role-play demonstration by professionals (with experience in engineering communication) to get a better initial understanding of the applications and benefits of being aware and affective in conversation."

Both the debriefing around students' discomfort and the modelling of the activities can be supported by reference to, and explicit discussion of, the underlying pedagogy of role plays and their demonstrated effectiveness in other educational contexts ${ }^{[31]}$.

Another key challenge in facilitating empathic learning experiences was concerned with the conceptions and practice of empathy challenging some of the students' ingrained assumptions 
about engineering work and their developing identities as engineers. A female student commented on how such prevalent expectations contrasted to her own personal attitudes and values:

"I had always had the impression that my being an empathetic person would be something I needed to separate out from my work. I was under the impression that the male-dominated engineering field would frown upon it."

A further challenge concerned the definitional character of problem solving in students' understanding of engineering and the difficulties in questioning assumptions around engineering expertise as they inform interactions with other stakeholders.

For example, when we invited students to engage with stakeholders in the context of engineering scenarios, the introduction to the exercises explicitly focused on relationship building and exploration of context as the overarching goals. Throughout the semester, however, we observed students implicitly framing these scenarios as a challenge in problem solving. One student commented on this aspect in his post-module reflection:

"Even though I love challenges, the thought of planning out how to feed a whole county in a few minutes was stressful.”

As instructors, we observed students' initial reflex to understand the situation as a problem solving challenge through the stress and sometimes frustration they expressed in engaging in the activities and in subsequent debriefing conversations. The challenge students experienced in letting go of this urge to solve "the problem" appeared not as a simple matter of explicitly reinforcing the educational purpose of the modules but as a deep seated and seemingly integral part of their self-perception as engineers. One student, after engaging in the series of exercises and debriefing sessions, still observed with a distinct sense of pride and achievement that,

"In the past modules I have learned that I am quick to solve problems as fast as possible without really taking the time to fully listen to others to completely understand their situation.”

Observing the students' struggles, we sought to make this facet of the students' responses to the exercises visible in the debriefing so that the group would be able to critically explore their associated assumptions about engineering. These conversations also served to alleviate some of the distress students experienced as a result of their way of framing the exercise. On a broader level of the course, a range of the semester readings and discussions focused on exploring and appreciating the importance of systems understanding and problem framing in the context of engineering work ${ }^{\text {e.g., } 29]}$.

In a similar way to observing the prominence of problem-solving as a "theory in action" [32] that students seemed to hold about engineering work, assumptions about the role of engineering expertise emerged as a significant obstacle to students' engaging in relationship building and empathy exercises. The notions of empathy that were presented in the model section above and that underpinned the design of the modules, inherently invite students to critically question 
beliefs around engineering expertise that frame engineers as separate from, or superior to, other stakeholders in socio-technical engineering contexts.

One student expressed these assumptions around engineers' authority resulting from expertise even through his experiencing a non-engineering role in the role play activity.

"With this module, I was also able to act as the local merchant. I could tell that the local merchant is much more clueless and doesn't necessarily know how to fix the problems Athens has. But once, the engineer offered a solution and made it appear that he knew how to solve the problems, it was like a veil of clouds were lifted."

Another student described his struggles with engaging in the role playas resulting from his expectations of a hierarchy of expertise in the socio-technical project context.

"I felt as if the situation wasn't exactly ideal to talk about. I feel like that "advisory team" wouldn't be a real thing in realistic situations. Who assembled this "advisory team," honestly? Why is an old man who's a hippie on it? Doesn't sound realistic at all. I feel like an appropriate advisement team would consist of the head engineer, financial manager, landscape engineer, an environmental analyst, and the principal of the school that the garden was being built for."

Moving through the modules, a number of students were not only able to expand their conceptions of their role of engineers but were also able to make their earlier conceptions explicit:

"I didn't previously consider members of the community to be experts on whatever local issue that is being dealt with. I guess I was more of a "traditional engineer" in the sense that I thought engineers were the experts because they have the necessary technical background to solve problems - everyone else was more or less in the way of the problem solution."

In facilitating the modules in an interdisciplinary teaching team, this aspect was particularly sensitive. In the debriefing sessions throughout the modules we sought to make explicit in discussions or demonstrate through our own role play examples how such assumptions around authority can severely limit the effective progression of socio-technical engineering projects. The scenarios offered students opportunities to recognize the value of interdisciplinary and community project partners, the limitations of narrow notions of expertise on developing effective relationships and the resulting limited and limiting understanding of the socio-technical problem.

While we can offer the above observations and pedagogical recommendations that will also inform our own efforts to further develop the modules, we feel that they also point to a range of broader, contextual challenges that can potentially limit the effectiveness and impact of efforts to explicitly foster empathy in engineering programs. 
As a community of engineering educators, we contend that there is a need to engage in a broadbased and systemic discussion around broadening our pedagogical concepts and approaches to significantly diversify students' learning experiences as some elements of broader learning outcomes ${ }^{[33,34]}$ will require fundamentally different learning formats and modalities. Our observations also suggest that we engage as a community to carefully consider the significant and often unintended impacts of curriculum and learning experiences on students selfperceptions ${ }^{[35]}$ and equally examine the expectations and assumptions around engineering, e.g. in terms of problem solving and expertise, that we as engineering educators create and shape in the ways that we talk about and enact engineering ${ }^{[36-38]}$.

\section{References}

1. Robbins, P.T., The Reflexive Engineer: Perceptions of Integrated Development. Journal of International Development, 2007. 19(1): p. 99-110.

2. Trevelyan, J., Technical Coordination in Engineering Practice. Journal of Engineering Education, 2007. 96(3): p. 191-204.

3. Kroes, P., et al., Treating socio-technical systems as engineering systems: some conceptual problems. Systems Research and Behavioral Science, 2006. 23: p. 803-814.

4. De Weck, O.L., D. Roos, and C.L. Magee, Engineering Systems: Meeting Human Needs in a Complex Technological World. 2011, Cambridge, MA: MIT Press.

5. Riley, D.M. and Y. Lambrinidou. Canons against Cannons? Social Justice and the Engineering Ethics Imaginary. in ASEE Annual Conference and Exposition. 2015. Seattle, WA.

6. Fila, N.D., et al., The People Part of Engineering: Engineering For, With, and As People in Frontiers in Education Annual Conference. 2014: Madrid, Spain.

7. Graham, R., The One Less Traveled By: The Road to Lasting Systemic Change in Engineering Education. Journal of Engineering Education, 2012. 101: p. 596-600.

8. Vanderburg, W.H. and N. Khan, How Well Is Engineering Education Incorporating Societal Issues? Journal of Engineering Education, 1994. 83: p. 357-361.

9. Walther, J., et al., Engineering Competence? An Interpretive Investigation of Engineering Students' Professional Formation. Journal of Engineering Education, 2011. 100(4): p. 703-740.

10. Levenson, R.W. and A.M. Ruef, Empathy: A physiological substrate. Journal of Personality and Social Psychology, 1992. 63(2): p. 234-246.

11. Segal, E.A., Social Empathy: A Model Built on Empathy, Contextual Understanding, and Social Responsibility That Promotes Social Justice. Journal of Social Service Research, 2011. 37(3): p. 266-277.

12. Walther, J., S.E. Miller, and N.W. Sochacka, A model of empathy in engineering as a core skill, practice orientation, and professional way of being. Journal of Engineering Education, (under review).

13. Miller, S.E., J. Walther, and N.N. Kellam. Social Work and Environmental Engineering: A Transdisciplinary Approach to Educating Reflective Practitioners. in Council on Social Work Education 58th Annual Program Meeting. 2012. Washington DC.

14. Walther, J., S.E. Miller, and N.N. Kellam. Exploring the Role of Empathy in Engineering Communication through a Transdisciplinary Dialogue. in American Society for Engineering Education Annual Conference and Exposition. 2012. San Antonio, TX.

15. Strobel, J., et al., Empathy and care within engineering: qualitative perspectives from engineering faculty and practicing engineers. Engineering Studies, 2013.

16. Decety, J. and Y. Moriguchi, The empathic brain and its dysfunction in psychiatric populations: Implications for intervention across different clinical conditions. BioPyshcoSocial Medicine, 2007. 1(22): p. 1-21.

17. Decety, J. and W. Ickes, eds. The Social Neuroscience of Empathy. 2009, The MIT Press: Cambridge, MA.

18. Fleddermann, C.B., Engineering Ethics. ESource--the Prentice Hall engineering source. 2008, Upper Saddle River, NJ: Pearson Prentice Hall. 
19. Harris, C., et al., Engineering Ethics: Concepts and Cases. 2013, Boston, MA: Cengage Learning.

20. Hashemian, G. and M. Loui, Can Instruction in Engineering Ethics Change Students' Feelings about Professional Responsibility? Science and Engineering Ethics, 2010. 16(1): p. 201-215.

21. Jonassen, D.H., et al., Engaging and Supporting Problem Solving in Engineering Ethics. Journal of Engineering Education, 2009. 98(3): p. 235-254.

22. van de Poel, I. and L. Royakkers, Ethics, Technology, and Engineering: An Introduction. 2011, Oxford: Wiley.

23. Whitbeck, C., Ethics in Engineering Practice and Research. 2011, Cambridge: Cambridge University Press.

24. Jonassen, D., J. Strobel, and C.B. Lee, Everyday Problem Solving in Engineering: Lessons for Engineering Educators. Journal of Engineering Education, 2006. 95(2): p. 139-151.

25. Laszlo, E., The systems view of the world: a holistic vision for our time. 1996: Hampton Press.

26. Winner, L., The whale and the reactor: a search for limits in an age of high technology. 1988: University of Chicago Press.

27. McDonough, W., M. Braungart, and B. Clinton, The Upcycle: Beyond Sustainability--Designing for Abundance. 2013: Farrar, Straus and Giroux.

28. Pool, R., Beyond Engineering: How Society Shapes Technology. 1999: Oxford University Press.

29. $\quad$ Pacey, A., Meaning in Technology. 2001: MIT Press.

30. Bornstein, D., How to change the world: social entrepreneurs and the power of new ideas. 2007: Oxford University Press.

31. Hargreaves, R. and J. Hadlow, Role-play in social work education: Process and framework for a constructive and focused approach. Social Work Education, 1997. 16(3): p. 61-73.

32. Schoen, D.A., The reflective practitioner: How professionals think in action. 1983, London: Temple Smith. 374.

33. National Academy of Engineering, Educating the engineer of 2020: adapting engineering education to the new century. 2005, Washington, DC: National Academies Press. 192.

34. ABET, Engineering criteria 2000 (EC2000). 1995, Accreditation Board for Engineering and Technology.

35. Walther, J., et al., Engineering Competence? An interpretive investigation of engineering students' professional formation. Journal of Engineering Education, 2011. 100(4): p. 703-740.

36. Sochacka, N.W., et al. Stories 'Told' about Engineering in the Media: Implications for attracting diverse groups to the profession. in Frontiers in Engineering Education Conference. 2014. Madrid, Spain.

37. Brewer, M., N.W. Sochacka, and J. Walther, Into the Pipeline: A freshman student's experiences of stories 'told' about engineering in American Society for Engineering Education Annual Conference \& Exposition. 2015: Seattle, WA.

38. Pawley, A.L., Universalized Narratives: Patterns in How Faculty Members Define “Engineering”. Journal of Engineering Education, 2009. 98(4): p. 309-319. 